\title{
Some Reflections on the Integration of Arts and Engineering in the Teaching of Industrial Design
}

\author{
Yi Liu ${ }^{1 *}$ \\ ${ }^{1}$ Fashion Accessory Art and Engineering College, Beijing Institute of Fashion Technology, Beijing, 100029, \\ China
}

\begin{abstract}
This paper analyzes the disciplinary characteristics of industrial design, and proposes to apply integration of arts and engineering in industrial design teaching. Then paper also analyzes its necessity; and conducts a comparative analysis of the characteristics of art and engineering students separately. Finally it proposes specific teaching methods for integration of arts and engineering.
\end{abstract}

\section{Features of the Industrial Design discipline}

Industrial design is a combination of art and engineering, but in undergraduate studies, many schools separate the art and engineering disciplines. Whether students with an art background or an engineering background come to study industrial design, there are both advantages and disadvantages, when it comes to innovation and creative design, different students will think differently about the problem and will consider the details from different perspectives. Design is focusing on problem solving, and art is self-expression. It is the means to analyze the problem in different ways.

The integration of arts and engineering is an important design principle in modern design. It was reflected early in the teaching practice of the Bauhaus period. The characteristics and philosophy of art-industrial integration have also shown unique advantages in guiding design research and practical application.

Industrial design is based on the disciplines of aesthetics, engineering, and economics, emphasizing the art form, technical function, and commercial value of products, and industrial products take human needs as a starting point, focusing on the functions and ways in which engineering can be implemented in people's lives and provide a pleasant experience.

Technology helps the product to be constantly upgraded, making the product usable, easy to use, and quick and convenient to solve problems; art increases the sense of temperature of the product, making people want to use the product more, and establishing an emotional relationship between people and the product. In the increasingly fierce business environment, the competitive trend of product consumption upgrade is not only in technological innovation in stride, but also in the experience of art forms to explore new commercial blue ocean. Technology and art are interdependent and play complementary roles in the material and spiritual aspects.

\section{Necessity of integration of arts and engineering}

The development of disciplines to this day has produced many emerging disciplines, and the development of technology has been driven more by the intersection of disciplines. The new goal of talent cultivation at this stage, covering the development of cross-disciplinary thinking, is very important for students to think innovatively and further study and research. In foreign countries, especially in Europe and the United States, there are many students who pursue interdisciplinary studies from the undergraduate to the postgraduate level in a way that is unimaginable in our domestic education, such as music students pursuing a doctorate in computer science to achieve electronic arranging, or mechanics students pursuing further studies in biomedicine to fulfill their dream of making prosthetic limbs for the disabled. This phenomenon is not an isolated case, and students are able to achieve these transitions because they receive a good general education at the undergraduate level, which provides a solid foundation for interdisciplinary research.

More than 80 per cent of students who have been studied abroad have a favourable view of interdisciplinary research, as these students have found varying degrees of interdisciplinary integration in their subjects, both on the job and in their further studies. Therefore, the development of cross-disciplinary mechanisms in existing talent training, both in terms of student recognition and the impact of cross-discipline on talent training, is a proven approach.

In the teaching of industrial design, the logical thinking and engineering knowledge of science students is very important, because industrial design is not designed

*axyly@bift.edu.cn 
for art but for mass-produced products. Although traditional industrial design is more oriented towards styling, the engineering technology, material properties, molding process, human-computer interaction, etc. many other factors need to be taken into account with the development of innovative styling. A reasonable solution is achieved by the result of form following function, aesthetics and the weighing of various factors. In the absence of rational logical thinking and a systematic knowledge structure at the time of design, the above factors can become a shackle to innovation.

In the actual group cooperation can be found, art classmates and polytechnic classmates in the study of industrial design, although there will be a certain degree of difference, but the difference is also a kind of progress space. Students of science and engineering use rigorous projections, design is very logical and rigorous, this is the art class should go to study seriously, while art students design the product shape and graphic design are very aesthetic, the need for science and engineering students to study more. In the process of cooperation can be more communication, more ideas collide, is likely to get more unexpected design inspiration and creative ideas. Therefore, the integration of arts and crafts is practicable in industrial design teaching.

\section{A comparative analysis of arts and engineering students}

In the design process, art students will be more diffuse, more emotional, and the design of products will be more beautiful and beautiful. As an engineering background, the thinking may be more rigorous, and more attention to detail in the performance of the product shape, the design will take into account the connection of parts or the process of molding, more relevant to the reality.

On the other hand, for art students, who are more emotional and dispersive, it is easier to produce wild design ideas, and there are more design ideas for the design of new concepts. In addition to taking advantage of their rational strengths in machinery and materials, engineering students should also open their minds more and generate more ideas for new concepts when making design innovations.

In terms of thinking, students with an artistic background will be more diffuse and innovative, with more design ideas and a wider range of design inspiration, while science students will be more rigorous in their thinking.

Art students are characterized by strong creativity, innovative thinking, and scattered thinking, but there are also unrealistic considerations; for engineering students, pragmatic and realistic, following the natural development of physical objects, but there is a lack of imagination and innovation. But art and engineering are organically integrated in real life, so through the reasonable setting of teaching content, the effective integration of students' newly acquired knowledge can be achieved.

\section{Recommendations for the integration of arts and engineering teaching}

Studying industrial design in the context of art-industrial integration is the same in terms of design methodology and design theory, but slightly different in terms of design thinking and focus of study. As a student with an engineering background, in the process of learning, first of all in terms of hand painting, art students have more than we have a painting base, hand painting ability is significantly stronger, the design is more beautiful, so more practice in hand painting practice needs to be invested in order to be more rapid in the stylistic expression of the product. Also in terms of colour sensitivity, improve your ability to match colours. In terms of product styling, a lot of styling accumulation should also be carried out to design the product styling can be more reasonable and beautiful.

In terms of hand-drawn expression, because of the difference in educational background since high school, students from art background have studied drawing for three or even more years, compared to the science subjects with zero basic hand-drawn, hand-drawn ability is obviously very strong, and design visuals are more beautiful, this is where the science subjects need to complement. But on the other hand, science students' hand-drawn expressions will be closer to reality and more rigorous. And the 3D modeling software is also more science-oriented and the final product expression will be more rational.

The integration of art and engineering is firstly reflected in the course learning, represented by courses on design aesthetics, product engineering technology and design, product CMF design research, intelligent hardware and interactive technology research and design trends, design language and design management, fully reflecting the artistic needs and technical support in industrial design. Industrial designers should not only develop artistic aesthetic ability, but also have knowledge of engineering technology, thinking of system design and interaction design technology. Secondly, the design of the structure, function and appearance of the product is made more specific and practical in the course through experimental research, technical operations and material process exposure.

By guiding students to participate in various competitions, the author has gained a new experience of art-industrial fusion. Our team, composed of art industrial design students and engineering information engineering students, has demonstrated the advantages and characteristics of art-industrial fusion team in terms of product proposal, technical analysis and construction, and final product presentation, etc. Members from different disciplinary backgrounds complement each other's ideas and opinions, identify points of convergence in crossdiscipline, reach design consensus, and timely solve the problems of design conceptualization and technical homogenization. Figure 1 gives the proposed structure of the integrated arts and engineering teaching. 


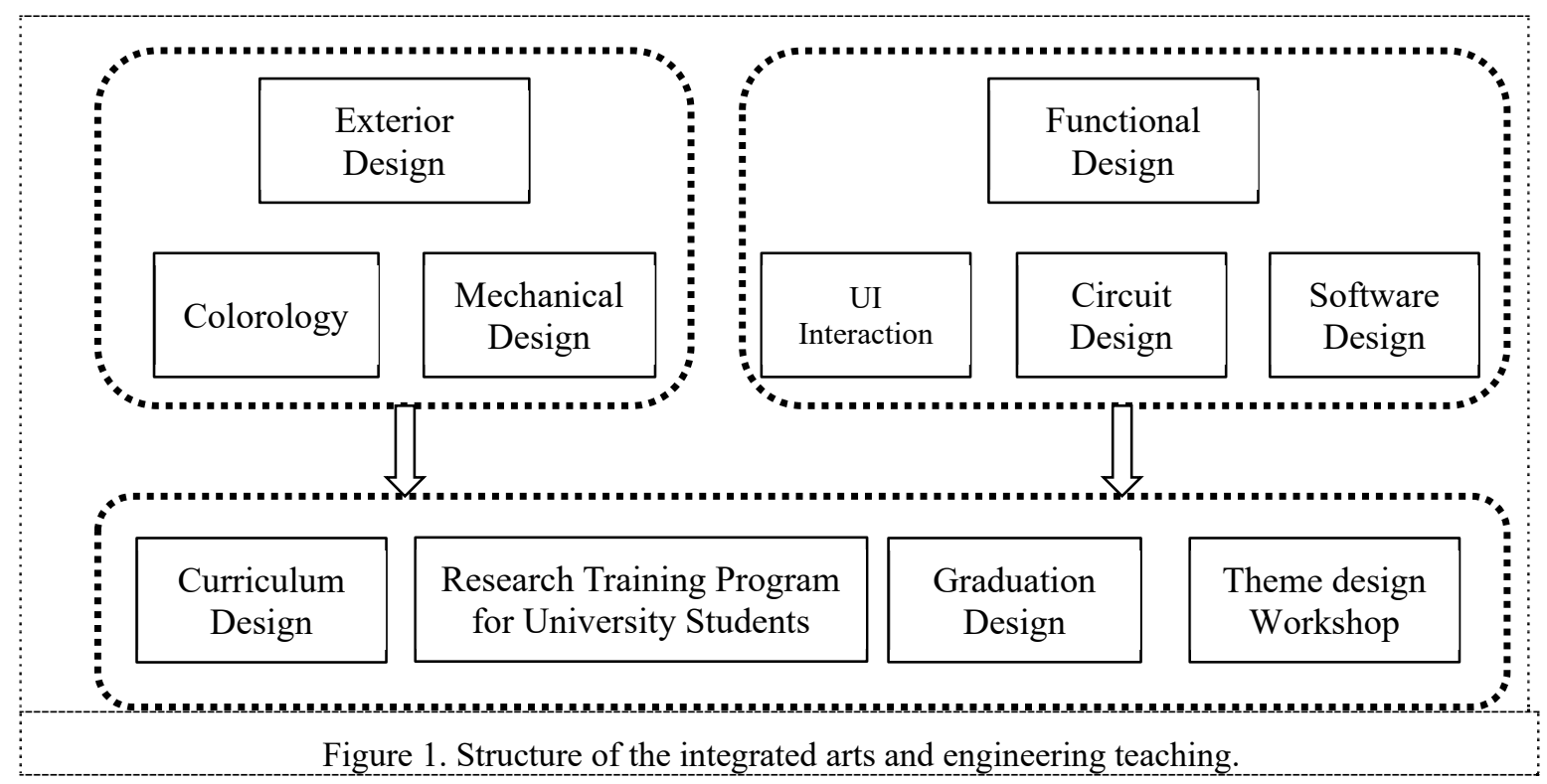

\section{Conclusion}

In the 13th Five-Year Plan period, one of the needs of higher education in China is: the huge demand for highlevel scientific and technological innovation talents brought about by innovation-driven development. Interdisciplinary education is one of the research hotspots in higher education and is also seen as an important way to develop innovative talents. In-depth study of the relationship between various disciplines such as art and engineering, the realization of multi-disciplinary interpenetration, complementarity and integration, so that students can acquire a more complete knowledge, so that students gradually form a dialectical and comprehensive way of understanding things when they understand and think about problems, and students can have a comprehensive development.

\section{Acknowledgments}

This research was financially supported by Beijing Institute of Fashion Technology College of Special Plan Young Top-notch Talent Project(BIFTBJ201803) , Beijing University of Higher Education Cross-cultivation Program for High-level Talents (2020-29), Beijing Institute of Fashion Technology Teaching Reform and Innovation Key Program (ZDJG-1709), and Fang Zhi Zhi Guang China National Textile And Apparel Council Higher Education Teaching Reform and Innovation Program (2017-08).

\section{References}

1. Kang Hui, Li Hongwei. (2004) Teaching concept and practice of a basic course on industrial design and modeling in engineering, decoration, 10:75-76.

2. Sun Xiaofeng, Zhao Ying, Zhou Miao etc. (2019) A study on the reform of industrial design professional talent cultivation mode in the context of new industrial science. Education and Teaching Forum, 37:

3. Liu Yumei, Jin Yujie. (2019) A Study on the Modern Industrial Design Professional Curriculum System in Local Applied Colleges and Universities in the Context of New Engineering . industrial design, 2019.

4. Chen Jing,(2020) Experimenting with the individual presentation of the integration of art and technology, Chinese Literature and Art Review, 3:92-100.

5. Zhou Wei, Bai Sen.(2020), Exploration on training model of " Technology and art integration" for undergraduate students in Digital Media Technology major. Experimental Technology and Management,3:212-214.

6. Zhou Lili,(2020), Research on the construction of a creative industrial design studio in the context of "Internet+Creator Space". Art Education Research, 6: 100-101.

7. Xie Hengyuan. (2020),Based on "morphological teaching"--Exploring basic teaching reforms in industrial design disciplines, Popular Science, 4:130.

8. Xie Li, (2020), A study on the teaching path of industrial design innovation and entrepreneurship 
practice in the context of new engineering, Contemporary Education Research and Teaching Practice, 8:166-167.

9. Xu Yuqing, Jin Ziyue and Gao Wenhan, (2020), A study on the process of graduation design assessment for industrial design undergraduates in the combination of industry, academia and research, Western China Quality Education. 8:173-174.

10. He Renke, (2019), Graduation Design Should Take the Initiative to combine virtual reality and other key technologies, Design, 20 : 36-37. 